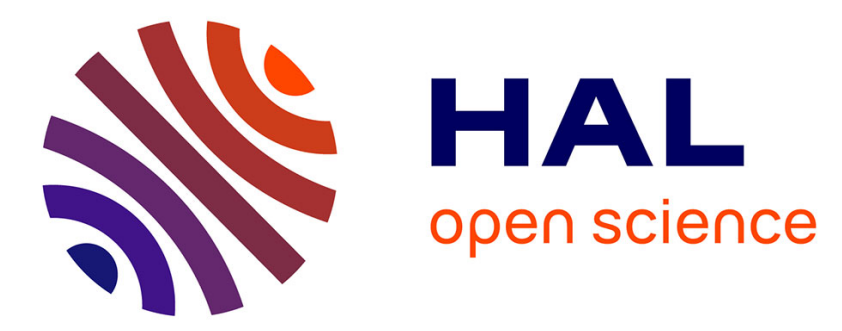

\title{
Direct vs Indirect Grafting of Alkyl and Aryl Halides
}

Dardan Hetemi, Catherine Combellas, Frédéric Kanoufi, Fetah I Podvorica

\section{To cite this version:}

Dardan Hetemi, Catherine Combellas, Frédéric Kanoufi, Fetah I Podvorica. Direct vs Indirect Grafting of Alkyl and Aryl Halides. ChemPhysChem, 2021, 22 (18), pp.1844-1849. 10.1002/cphc.202100296 . hal-03385768

\section{HAL Id: hal-03385768 \\ https://hal.science/hal-03385768}

Submitted on 19 Oct 2021

HAL is a multi-disciplinary open access archive for the deposit and dissemination of scientific research documents, whether they are published or not. The documents may come from teaching and research institutions in France or abroad, or from public or private research centers.
L'archive ouverte pluridisciplinaire HAL, est destinée au dépôt et à la diffusion de documents scientifiques de niveau recherche, publiés ou non, émanant des établissements d'enseignement et de recherche français ou étrangers, des laboratoires publics ou privés.

\section{(1)(1) $\$(0)$}

Distributed under a Creative Commons Attribution - NonCommercial - ShareAlikel 4.0 


\title{
Direct vs indirect grafting of alkyl and aryl halides
}

\section{Dardan Hetemi, ${ }^{a}$ Catherine Combellas, ${ }^{b}$ Frédéric Kanoufi, ${ }^{b}$ Fetah I. Podvorica ${ }^{c, d e, *}$}

In memoriam of Prof. Jean-Michel Savéant

a) Pharmacy Department, Medical Faculty, University of Prishtina "Hasan Prishtina", Rr.

"Dëshmorët e Kombit" p.n., 10000 Prishtina, Kosovo

b) Université de Paris, ITODYS, CNRS, UMR 7086, 15 rue J-A de Baïf, F-75013 Paris, France

${ }^{c}$ Department of Chemistry, Faculty of Mathematical-Natural Sciences, University of Prishtina "Hasan Prishtina", 10000 Prishtina, Kosovo.

d) Academy of Sciences and Arts of Kosova, Rr. "Agim Ramadani” nr 305, 10000 Prishtina, Kosovo

e) NanoAlb-Unit of Albanian Nanoscience and Nanotechnology, 1000 Tirana, Albania

\begin{abstract}
The direct and indirect electrochemical grafting of alkyl and aryl halides (RX, ArX) on carbon, metal and polymer surfaces is examined. Their electrochemical reduction occurs at highly negative potential in organic solvents and very often produces carbanions because the reduction potentials of $\mathrm{RX}$ and $\mathrm{ArX}$ are more negative than those of their corresponding radicals. Therefore, direct electrografting of alkyl and aryl radicals generated from RX and ArX is not easy to perform. This obstacle is overcome using aryl radicals derived from the 2,6dimethylbenzenediazonium salt (2,6-DMBD), which do not react on the electrode surface due to their steric hindrance but react in solution by abstracting an iodine or bromine atom from RX (X= I, Br) or ArI to give alkyl or aryl radicals. As a consequence, alkyl and aryl radicals are generated at very low driving force by diverting the reactivity of aryl radicals derived from an aryl diazonium salt; they attack the electrode surface and form strongly attached organic layers. This strategy applies to the chemical modification of polymers (polyethylene, polymethylmethacrylate) by alkyl halides under heating.
\end{abstract}

Key words: direct reduction, indirect reduction, alkyl halides, aryl iodides, steric hindrance.

*Corresponding author: fetah.podvorica@uni-pr.edu 


\section{Introduction}

Electrochemical reduction of alkyl and aryl halides, $\mathrm{RX}$ and $\mathrm{ArX}$, can be carried out at quite highly negative potentials in organic solvents. Injection of an electron to the molecule provokes the cleavage of the carbon-halogen bond and makes possible the formation of the corresponding alkyl or aryl radical. Carbon halogen bond breaking may occur simultaneously with the electron transfer (ET, concerted electron transfer, reaction (1) in Scheme 1) ${ }^{[1,2]}$ or successively (stepwise mechanism, reactions (2) and (3) in Scheme 1) via a radical anion intermediate: ${ }^{[2]}$

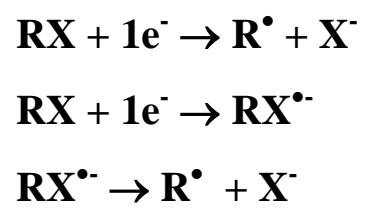

The electrochemical reduction of RX almost always occurs through the concerted mechanism ${ }^{[3]}$ while this is not always the preferred path for $\mathrm{ArX}^{[4]}$ The main reason for these different behaviors is the orbital where the incoming electron is accommodated. In the case of alkyl halides it goes into the $\mathrm{C}-\mathrm{X} \sigma^{*}$ orbital of high energy leading to the cleavage of the bond. ${ }^{[5]}$ Conversely, aryl halides have $\pi^{*}$ orbitals of lower energy where the electron is hosted during the electrochemical reduction, which increases the $\mathrm{ArX}^{\bullet-}$ lifetime and makes the stepwise mechanism possible. ${ }^{[2]}$ The $\mathrm{ArX}^{\bullet-}$ dissociation happens when the extra electron is transferred to the $\mathrm{C}-\mathrm{X} \sigma^{*}$ orbital. Carbon halogen bond cleavage rate constants of different $\operatorname{ArX}^{\bullet-}$ in aprotic solvents vary greatly depending on the substituents on the benzene ring: it is $>10^{10} \mathrm{~s}^{-1}$ for chlorobenzene and $<10^{-4} \mathrm{~s}^{-1}$ for 4-chloronitrobenzene. ${ }^{[6]}$

Radicals in solution may react with nucleophiles, $\mathrm{Nu}^{-}$, to give $\mathrm{RNu}^{\bullet-}$ (radical nucleophilic substitution $\left.\mathrm{S}_{\mathrm{RN}} 1\right)$, ${ }^{[1]}$ dimerize, disproportionate or attack olefins, they can also undergo a reduction at the electrode surface to give carbanions:

$\mathbf{R}^{\bullet}+1 \mathbf{e}^{-} \rightarrow \mathbf{R}^{-}$

$A r^{\bullet}+1 e^{-} \rightarrow A r^{-}$

The latter reactions are the dominating ones for the radicals that are reduced at the same or less negative potentials than RX or ArX. ${ }^{[7-12]}$

For alkyl halides, cyclic voltammetry permits to evidence the impact of the nature of alkyl groups on the reduction potential and to measure the number of incoming electrons from the electrode. The reduction is more and more difficult from tertiary to secondary and primary 
halides. Concerning the halogen atom, iodides are the easiest to be reduced followed by bromides and chlorides. The number of electrons transferred from the electrode permits to discriminate between the formation of radicals (one-electron transfer) and carbanions (twoelectron transfer). For example $t$-butyliodide in DMF shows a monoelectronic wave on GC electrode at $-1.91 \mathrm{~V} / \mathrm{SCE}$ followed by a small wave at $-2.5 \mathrm{~V} / \mathrm{SCE}$ while s-butyl iodide is reduced at more negative potentials along two monoelectronic waves, at -2.05 and $-2.4 \mathrm{~V} / \mathrm{SCE}$, and n-butyl iodide gives a two-electron wave at $-2.33 \mathrm{~V} / \mathrm{SCE}$. $t$-Butyl, $s$-butyl and $n$-butyl bromides give bielectronic waves at potentials lower than $-2.5 \mathrm{~V} / \mathrm{SCE} .{ }^{[3]}$ Reduction potential of alkyl iodides and bromides depends on the nature of the electrode and is much lower with Ag, $\mathrm{Cu}$ and Pd electrodes, which enables the observation of two well separated one-electron waves due to a positive potential shift $>1 \mathrm{~V} .^{[13-17]}$

Electrochemical reduction of aryl halides also occurs at different driving forces on $\mathrm{GC}, \mathrm{Ag}, \mathrm{Au}$, $\mathrm{Pt}$, $\mathrm{Pd}$ or $\mathrm{Cu}$ electrodes. ${ }^{[18-21]}$ The metal surface enables the activation of the $\mathrm{C}-\mathrm{X}$ bond and permits the formation of an aryl-aryl linkage. ${ }^{[21]}$ The electrochemical affinity of aryl halides to produce aryl carbanions has been used for the electrosynthesis of organic products such as benzoic acid obtained by one pot-reduction of an aryl bromide on silver electrode; ${ }^{[22]}$ the phenyl anion derived from electrochemical reduction of bromo or iodobenzene on cadmium cathode in acetonitrile enables the formation of the cyanomethyl anion as a precursor for coupling reactions with electrophilic compounds. ${ }^{[23]}$

\section{Direct electrografting of RX}

Steric hindrance makes impossible the electrografting of tertiary and secondary alkyl radicals containing more than three carbon atoms while n-alkyl radicals obtained at very negative potentials, if they survive their reduction to carbanions, may react with electrodes. Therefore, the direct electrochemical grafting of alkyl halides on GC electrodes is not an easy task and the examples reported in the literature mainly concern primary alkyl halides.

Let us mention dodecyl radicals obtained on mercury electrode by reduction of 1-iodododecane in DMF at $\mathrm{E}=-2.3 \mathrm{~V} / \mathrm{SCE}$, which provide dodecyl mercury compounds. ${ }^{[24]}$

The electrochemical activation of different primary alkyl iodides or bromides on graphene and

metallic electrodes caused the attachment of the alkyl layer on $\mathrm{Au},{ }^{[25-26]} \mathrm{Cu},{ }^{[25]} \mathrm{carbon}^{[13,25-29]}$ $\mathrm{Pd}^{[13-15]}, \mathrm{Cu}^{[13,16]}$ and $\mathrm{Ag}^{[13,15,17,30,31]}$ surfaces. Alkyl iodides in an ACN solution on a gold 
electrode present a current peak at Ep $\sim-2.5 \mathrm{~V} / \mathrm{SCE}^{[25]}$, see Figure 1 for $\mathrm{IC}_{6} \mathrm{H}_{13}$. After 10 consecutive scans (without stirring the solution) the current decreases as a result of electrode passivation. XPS and IRRAS indicate the presence of an alkyl layer on the electrode surface. This implicitly shows that during the transformation of alkyl radicals to carbanions at such negative potential, a small part of these highly reactive species escapes reduction and reacts with the electrode surface, resulting in the grafting of electrode.

In the case of perfluoroalkyl iodides, their reduction potential is less negative than that of alkyl

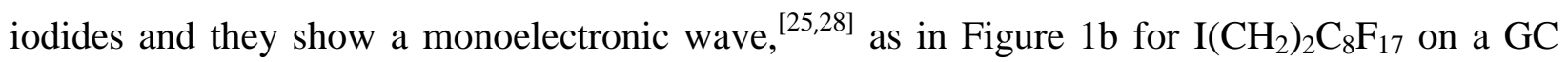
electrode. The composition of the grafted layer was characterized by XPS, IRRAS and ToFSIMS. ${ }^{[25]}$ These alkyl layers are more compact on copper and show hydrophobic properties (from contact angles), especially those containing perfluoroalkyl groups.
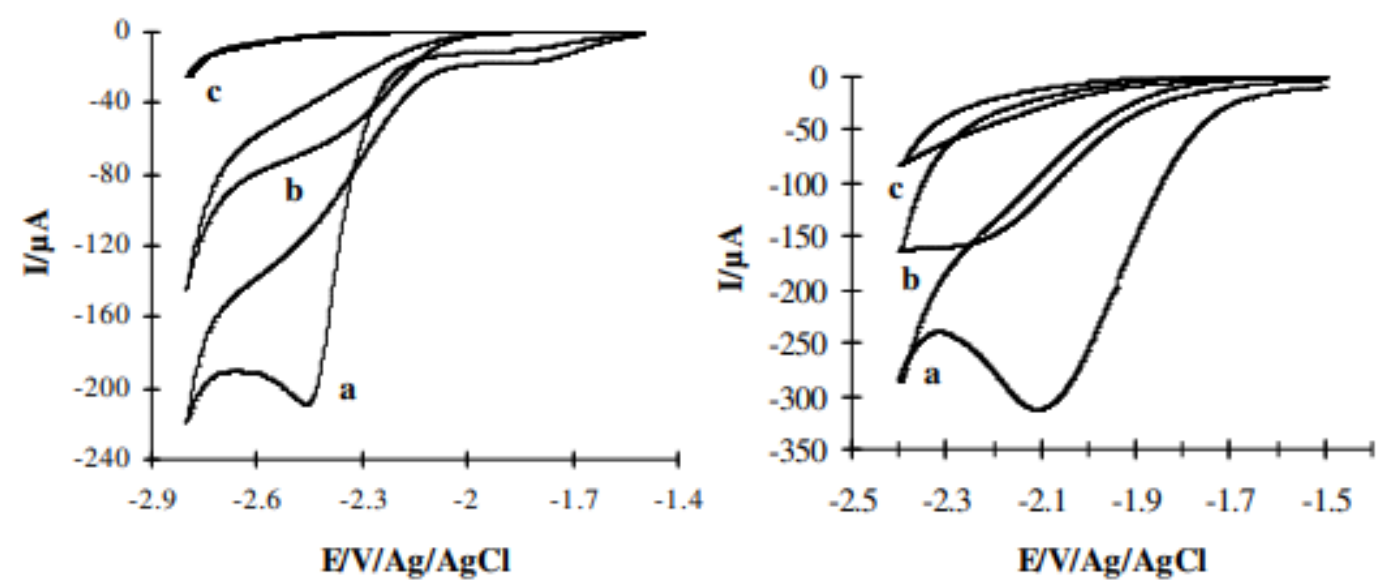

Figure 1. Cyclic voltammetry in $\mathrm{ACN}+0.1 \mathrm{M} \mathrm{NBu}_{4} \mathrm{BF}_{4}$ on $\mathrm{A}$ ) a gold electrode (diameter, $d=1 \mathrm{~mm}$ ) of $n$ - $\mathrm{IC}_{6} \mathrm{H}_{13}(c=10 \mathrm{mM})$ : (a) $1^{\text {st }} \mathrm{scan}$; (b) $10^{\text {th }} \mathrm{scan}$, and (c) in the absence of $\mathrm{IC}_{6} \mathrm{H}_{13}$; B) a GC electrode $(d=$

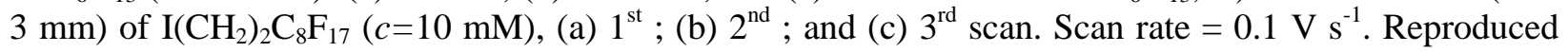
with permission from Ref. [25]. Copyright 2008 ACS.

Modification of metal surfaces by direct electrochemical reduction of alkyl iodides involves alkyl radicals while the surface modification of carbon goes through the attack of RI by the negatively charged $\mathrm{sp}^{2}$ carbon atoms acting as nucleophiles, along a $\mathrm{S}_{\mathrm{N}} 2$-like reaction. ${ }^{[28,32]}$ Electrochemical reduction of alkyl halides is made much easier on palladium and silver electrodes due to electrocatalysis. For example n-butyliodide is reduced with a positive potential shift of $0.7 \mathrm{~V}$ at Pd electrode ${ }^{[15]}$ and 1.35 at $\mathrm{Ag}$ electrode $\mathrm{V} \cdot{ }^{[17]} \mathrm{A}$ detailed mechanism was established for the electrochemical reduction of benzyl chloride on silver electrode based on 
electrochemical data, surface-enhanced Raman spectroscopy (SERS) and density functional theory (DFT) calculations. ${ }^{[30,33,34]}$ The key step that contributes to electrocatalysis of silver electrode is the weak adsorption of benzyl chloride molecules on $\mathrm{Ag}$ and the formation of adducts with Ag surface atoms during the cathodic potential excursion prior to their electrochemical reduction. SERS also indicates a benzyl-silver radical adduct, which is transformed to benzyl anion by the injection of the second electron. ${ }^{[30]}$ Due to these silver-benzyl chloride interactions there is a $0.5 \mathrm{~V}$ positive potential shift compared to GC electrode. The use of such catalysts to reduce alkyl halides enables the generation of alkyl radicals at the potential where they cannot be reduced so that they attack the electrode surface and create a grafted alkyl layer. $^{[13,35]}$

\section{Direct electrografting of ArX}

Aryl iodides can be grafted onto GC surface when the electrode is biased at very negative potentials, $\mathrm{Ep}=-2.3 \mathrm{~V} / \mathrm{SCE}$ for iodobenzene, and its complete passivation is achieved upon 100 scans in cyclic voltammetry, see Figure 2. ${ }^{[36]}$ Almost all aryl radicals that are produced after the first electron transfer from the cathode are immediately reduced to carbanions, ${ }^{[7]}$ which are transformed to benzene after protonation. ${ }^{[37]}$ However, repetitive scanning indicates a small decrease of cathodic current, which is significant after > 50 cycles: during the first scans the very small number of residual aryl radicals that escape the reduction start to passivate the electrode surface, which makes the reduction process more difficult, increases the number of surviving phenyl radicals and permits the growth of an aryl layer. ${ }^{[36]}$ This grafted layer was characterized by XPS and the film thickness measured by ellipsometry varies from 1 up to $13 \mathrm{~nm}$ after $10 \mathrm{~min}$ electrolysis. The main reason for this variation of film thickness is the quantity of bromophenyl radicals that are generated during the electrochemical reduction of 1-bromo-4-iodobenzene, which occurs at much higher extent during electrolysis. The grafted aryl layer is strongly attached to the GC surface as it resists longtime ultrasonication and has a well-ordered structure that is attested by the linear increase of surface concentration of ferrocenylmethyl benzoate with the film thickness. ${ }^{[36]}$ 


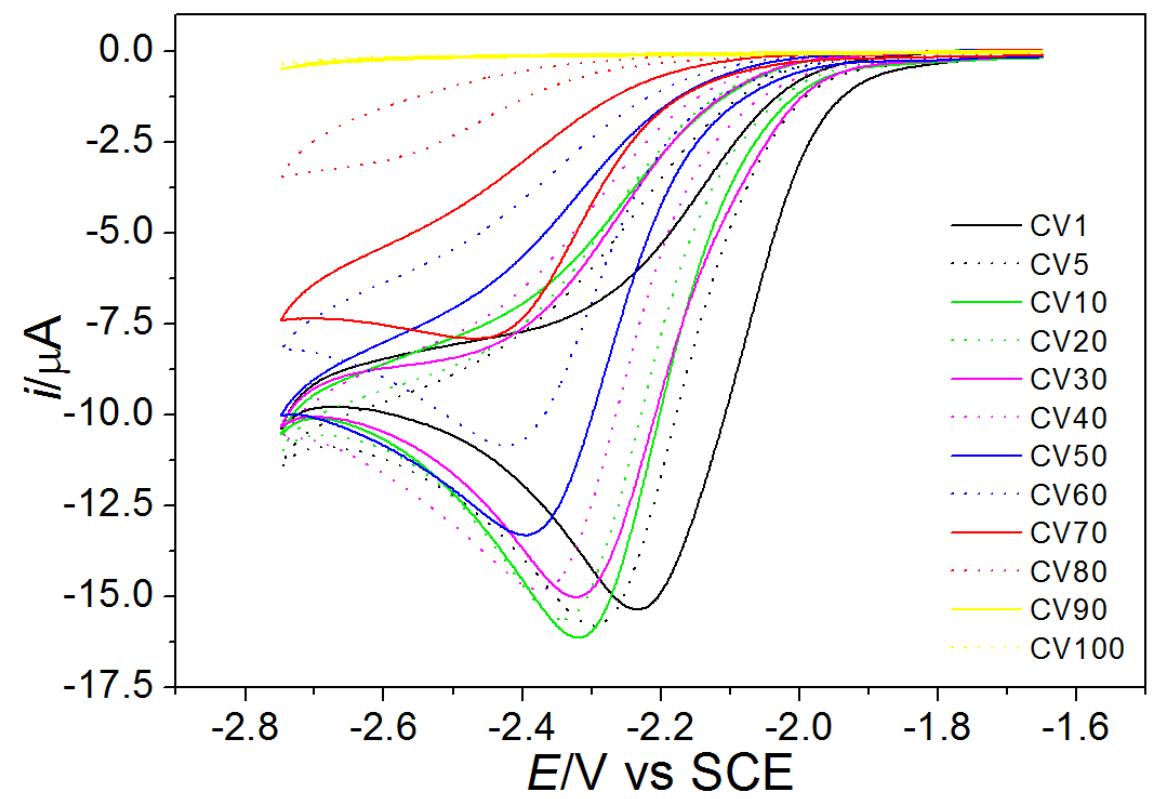

Fig. 2. Cyclic voltammograms recorded at a $\mathrm{GC}$ electrode $(d=1 \mathrm{~mm})$ immersed in $\mathrm{ACN}+0.1 \mathrm{M}$ $\mathrm{NBu}_{4} \mathrm{BF}_{4}+2 \mathrm{mM}$ iodobenzene. Scan rate $=0.1 \mathrm{~V} \mathrm{~s}^{-1}$. Reproduced with permission from Ref. [36]. Copyright 2017 ACS

\section{Indirect grafting of $\mathbf{R X}$}

The formation of aryl radicals from aryl diazonium salts $\left(\mathrm{Ar}-\mathrm{N} \equiv \mathrm{N}^{+}\right)$by electrochemical reduction is much easier than from ArX. This reaction can be performed on various types of carbon, metals and semiconductor surfaces. ${ }^{[38]}$ Electrochemically generated aryl moieties are prone to attack the electrode surface but also undergo different chemical reactions in solution such as dimerization, attack of aromatic ring via cyclohexadienyl intermediates, Gomberg-

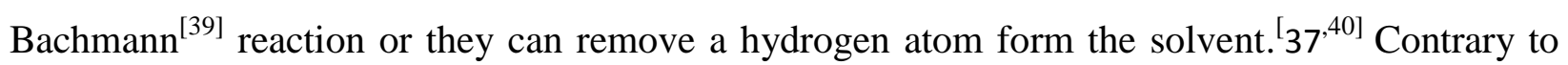
aryldiazonium salts, alkyldiazonium salts are very instable and they are immediately decomposed in the solution after their synthesis $;{ }^{[41]}$ therefore their electrochemical reduction and the grafting of issued alkyl radicals is impossible. Their synthesis and electrochemical grafting was possible only when nitrite ions were electrochemically generated on copper surface at $\sim$ $0.8 \mathrm{~V} / \mathrm{Ag} / \mathrm{AgCl}$ and immediately reacted with primary alkyl amine forming an alkyl diazonium salt, the reduction of which gives an alkyl radical. ${ }^{[42]}$

Almost all aryldiazonium salts, once they are reduced, generate aryl radicals and form a grafted layer on the electrode surface; however 2,6-dimethylbenzenediazonium (2,6-DMBD) with two 
methyl groups ortho of the diazonium group leads to the sterically hindered 2,6-dimethylphenyl radical that does not react with surfaces, see Figure $3{ }^{[43]}$

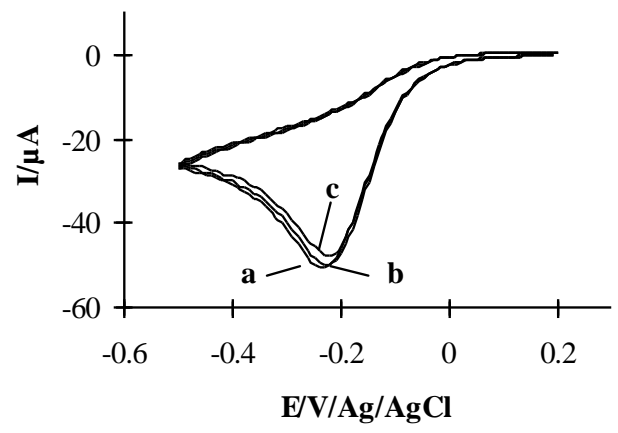

Fig. 3. Cyclic voltammetry on a glassy carbon electrode $(d=2 \mathrm{~mm})$ in $\mathrm{ACN}+0.1 \mathrm{M} \mathrm{NBu}_{4} \mathrm{BF}_{4}$ of $4 \mathrm{mM}$ 2,6-DMBD, (a) $1^{\text {st }}$, (b) $2^{\text {nd }}$, and (c) $10^{\text {th }}$ scan. Scan rate $=0.1 \mathrm{~V} \mathrm{~s}^{-1}$. Reproduced with permission from Ref. [43]. Copyright 2009 ACS

This phenomenon can be evidenced by cyclic voltammetry; contrary to other diazonium salts one can notice the presence of an irreversible cathodic wave that retains the same shape and intensity after 10 consecutive scans. XPS and IRRAS on GC and copper plates prepared under the above conditions do not indicate any organic grafting. The absence of surface modification is supported by DFT calculations, which confirm a decrease of more than $50 \%$ of the bonding energy in the case of the 2,6-dimethylphenyl group by comparison with a phenyl moiety. ${ }^{[43]}$ This behavior of the 2,6-dimethylphenyl radical regarding surface grafting does not concern homogeneous reactions; particularly, steric effects are not an obstacle to perform the reaction of this radical with alkyl halides in solution.

Iodine Abstraction. As discussed above, during direct electrografting of alkyl iodides on metals and glassy carbon at highly negative potentials, most alkyl radicals are reduced to their anion, making quite difficult the modification of the electrode surface with alkyl layers. Nevertheless, the formation of alkyl radicals was performed at lower driving force by generating 2,6dimethylphenyl radicals in the presence of alkyliodides. This is exemplified here in the case of 1-

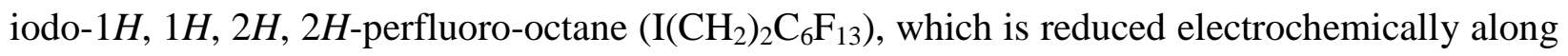
an irreversible two-electron wave, Ep -1.95 V/Ag/AgCl (Figure 4Aa) whilst 2.6-DMBD is reduced irreversibly in a one-electron process, Ep $\sim-0.22 \mathrm{~V} / \mathrm{Ag} / \mathrm{AgCl}$ (Figure 4Ab). ${ }^{[44]}$ The reduction peak of 2.6-DMBD is smaller in Figure 4Ab than expected, which suggests a father- 
son reaction in solution due to the attack of the diazonium by one of its reduction products. ${ }^{[45,46]}$ In a mixture of perfluoroalkyliodide and 2,6-DMBD, the cathodic current decreases continuously with the number of scans due to the passivation of the electrode surface (Figure 4B).
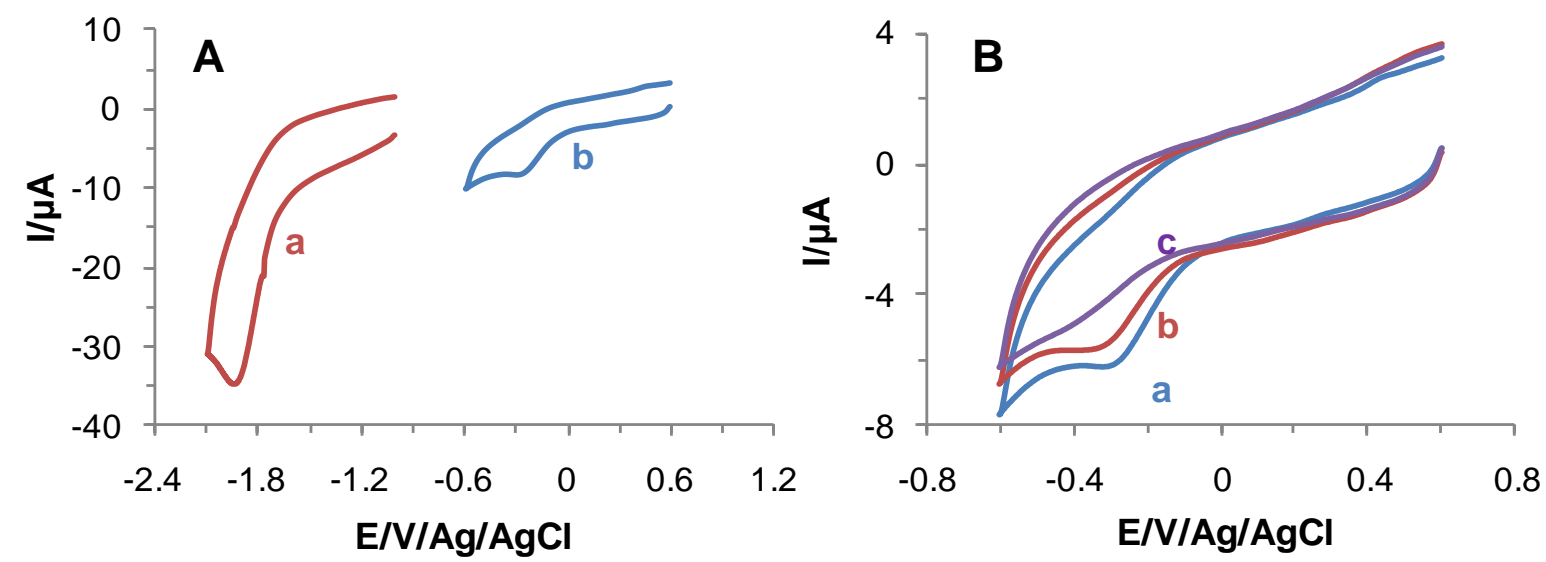

Fig. 4. Cyclic voltammetry on a $G C$ electrode $(d=2 \mathrm{~mm})$ in $\mathrm{ACN}+0.1 \mathrm{M} \mathrm{NBu}_{4} \mathrm{PF}_{6}$ of $\mathrm{I}\left(\mathrm{CH}_{2}\right)_{2} \mathrm{C}_{6} \mathrm{~F}_{13}$ and 2,6-DMBD (1 mM each). (A) each species recorded separately: (a) $\mathrm{I}\left(\mathrm{CH}_{2}\right)_{2} \mathrm{C}_{6} \mathrm{~F}_{13}$, (b) 2,6-DMBD. (B) Mixture of both species (a) $1^{\text {st }}$, (b) $2^{\text {nd }}$ and c) $8^{\text {th }}$ scan. Scan rate $=0.2 \mathrm{~V} / \mathrm{s}$. Reproduced with permission from Ref. [44]. Copyright 2014 ACS

Surface analysis (XPS, IRRAS) confirms the presence of fluoroalkyl moieties on the electrode surface while the iodine atom signal is missing. The organic layer is several $\mathrm{nm}$ thick and is strongly attached to the electrode as it resists to $2 \mathrm{~h}$ in boiling toluene. Redox probe measurements performed with ferricyanide showed a significant decrease of its signal when the GC electrode was tethered with alkyl layer. These data (supplemented by water contact angles) indicate that the $G C$ surface is tethered by alkyl groups at the reduction potential of 2,6-DMBD, which is much less negative than that of alkyliodide, $\Delta \mathrm{Ep} \sim 1.7 \mathrm{~V} .^{[44]}$ This catalytic effect is possible by diverting the reactivity of aryl radicals and is much higher than that observed in the presence of metals such as Ag or Pd. ${ }^{[13,15,30,31]}$

The grafting mechanism summarized in Scheme 1: the 2,6-dimethylphenyl radical (2,6- $\left.\mathrm{DMPh}^{\bullet}\right)$ is generated during the electrochemical reduction of 2,6-DMBD (reaction 6); it abstracts an iodine atom from the alkyl iodide and creates an alkyl radical (reaction 7); such alkyl radical produced in the vicinity of the electrode surface reacts with this surface to give an organic layer, (reaction 8). 
These reactions also occur in homogeneous solution by reaction of aryl radicals derived from different aryl diazonium salts and alkyl iodides. ${ }^{[47]}$ For example, the diazonium salt is first transformed to diazene in the presence of a Hantzsch ester, which acts as a $\sigma$-bond nucleophile and diazene is further transformed to an aryl radical in the presence of oxygen. ${ }^{[48]}$ Diazonium salts containing electron-rich and sterically hindered mesityl groups enhance the reaction between aryl radicals and alkyl iodides. ${ }^{[47]}$ The reaction was performed in an open vessel, at room temperature, and the products were characterized by ${ }^{1} \mathrm{H}$ and ${ }^{13} \mathrm{C}$ NMR once isolated by chromatography. These results obtained in homogeneous medium confirm the approach of the indirect grafting method based on the reaction between alkyliodides and 2,6-DMBD.

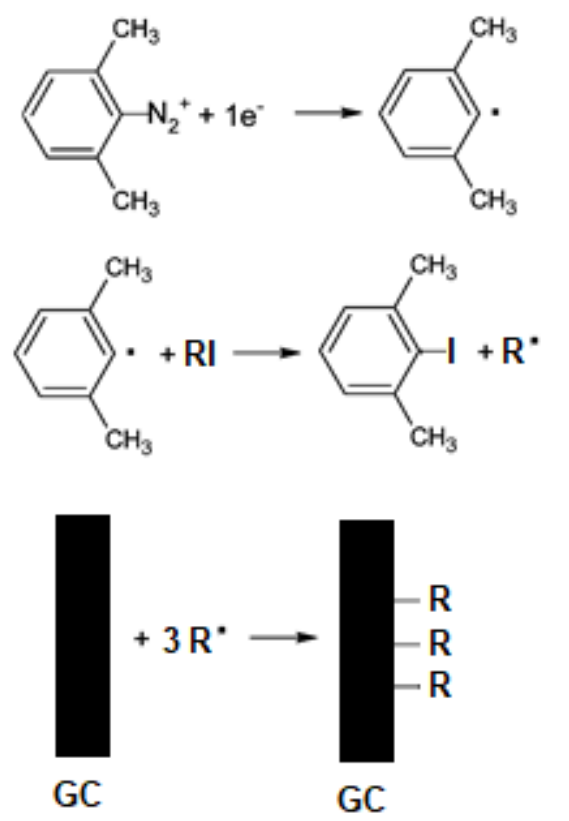

Scheme 1: Mechanism for the indirect grafting of alkyl radicals on $G C$ surface.

The electrografting of alkyl moieties is also possible by diverting the reactivity of aryl radicals derived from other diazonium salts, such as those that are prone to react with surfaces. An example is reported when using 4-nitrobenzenediazonium and 4-methylbenzenediazonium salts. ${ }^{[49]}$ Aryl radicals undergo two reactions: i) with the surface, ii) with alkyliodides in solution to generate alkyl radicals by iodine abstraction. This approach permits the formation of mixed alkyl-aryl layers and by controlling the ratio of aryldiazonium salt and alkyl iodide it is possible to tune the properties of the modified surfaces. The formation of a mixed layer containing nitrophenyl and perfluoroalkyl moieties with different compositions was also attested by water 
contact angles: its value increases from $80 \pm 1^{\circ}$ for nitrophenyl layer to $121 \pm 3^{\circ}$ when the concentration of perfluoroalkyliodide was 50 times higher than that of 4-nitrobenzenediazonium.

Bromine Abstraction. Removal of a halogen atom from an alkyl halide by 2.6-dimethylphenyl radical is not restricted to alkyl iodides but also occurs with alkyl bromides, which are more difficult, even impossible to graft by electrochemical reduction. ${ }^{[3,50]}$ As alkyl bromides are easily available with different terminal functional groups, they can provide a tethered film that can be further modified. For example, the same procedure as above, starting from 6-bromo-1-hexanoic acid, provides a gold electrode modified with hexanoic acid groups. The presence 2-D organic layer strongly attached on gold surface is attested by IRRAS and XPS while its thickness measured by ellipsometry is about $3 \mathrm{~nm}$ while water contact angle measurements indicate the presence of hydrophilic moieties. ${ }^{[} 50^{]}$Thermal decomposition at $60^{\circ} \mathrm{C}$ of 2,6-DMBD prepared in situ, in the presence of 6-bromo-1-hexanoic acid, permits the grafting of hexanoic acid groups on the surface of high density polyethylene (PE) and polymethyl methacrylate (PMMA). ${ }^{[51]}$ The hexanoic groups attached to a gold surface were further post-modified with aminoferrocene, anthraquinone or polyethylene glycol (PEG) groups by peptidic coupling. ${ }^{[51]}$ They also were used to prepare layer-by-layer (LbL) assembly when the modified gold plate was immersed in polyelectrolyte solutions containing alternatively branched polyethyleneimine (PEI) and poly(acrylic acid) (PAA). These LbL layers present a certain capacity to retain $\mathrm{Ru}\left(\mathrm{NH}_{3}\right)_{6}{ }^{2+/ 3+}$ ions within the assembly. ${ }^{[51]}$

\section{Indirect grafting of aryl iodides}

As indicated above, aryl radicals issued from aryl iodides by electrochemical reduction undergo a surface reaction with low yield. ${ }^{[36]}$ A completely different behaviour is observed when using 2,6-DMBD as precursor of the 2,6-dimethylphenyl radical in the presence of iodobenzene in ACN : it is possible, after few cyclic voltammograms, to graft aryl groups along a mechanism similar to that of Scheme 2. ${ }^{[52]}$
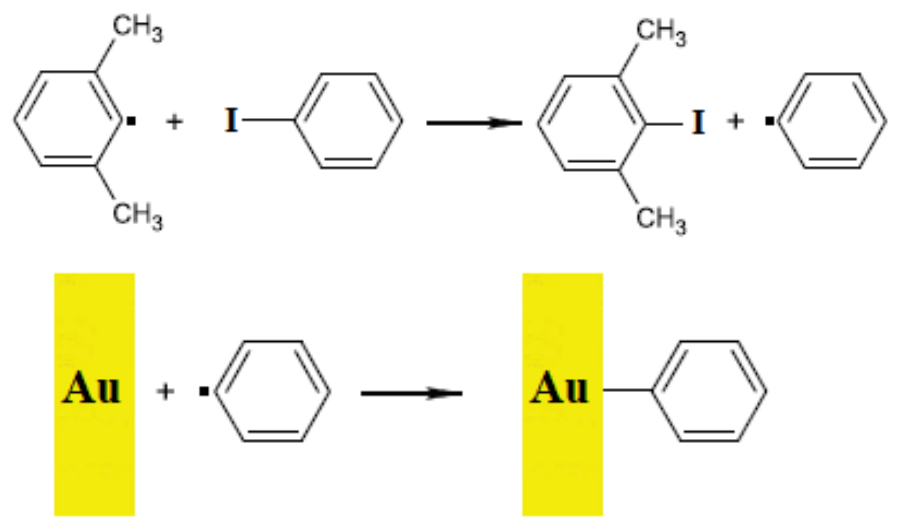
Scheme 2. Indirect grafting of aryl radicals derived from aryl iodides on gold surface.

The same procedure allows grafting 4-iodoaniline (which is used as precursor of the 4benzenediazonium salt) and 4-iodonitrobenzene (that cannot be directly electrografted because during its electrochemical reduction it is transformed to nitrobenzene via an ECE mechanism). ${ }^{[53]}$ Such indirect modification of surfaces with aromatic layers is particularly suitable for pyridine derivatives compared to the reaction with their corresponding diazonium salts, which are very unstable. ${ }^{[54,55]}$ Figure 5 shows the passivation of a gold electrode with 2 -aminopyridine radicals generated from 5-iodo-2-aminopyridine after the abstraction of iodine atom by the 2,6dimethylphenyl radica] layer by IRRAS and X amino groups. ${ }^{[52]}$

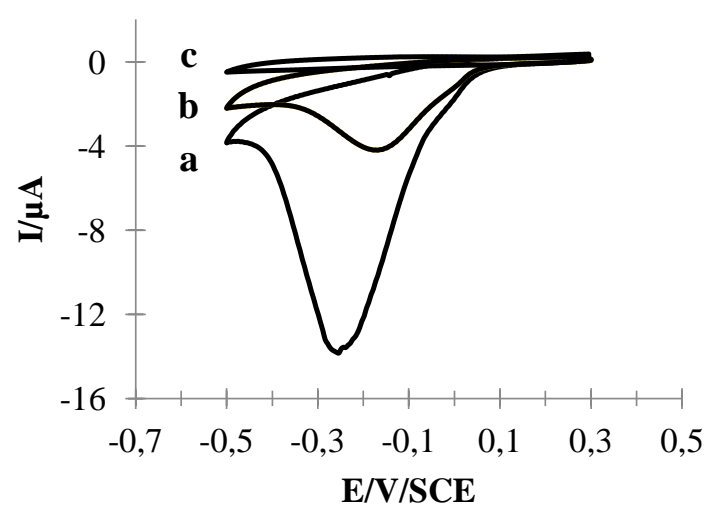
ttion of the grafted organic riginated from pyridine and

Fig. 5. Cyclic voltammetry on Au electrode $(d=1 \mathrm{~mm})$ in $\mathrm{ACN}+0.1 \mathrm{M} \mathrm{NBu}_{4} \mathrm{PF}_{6}+10 \mathrm{mM} 2,6-\mathrm{DMBD}+$ $20 \mathrm{mM}$ 5-iodo-2-aminopyridine: a) $1^{\text {st }}$, b) $2^{\text {nd }}$ scan and c) 5-iodo-2-aminopyridine $(20 \mathrm{mM})$ without 2,6DMBD. Reproduced with permission from Ref. [52]. Copyright 2018 Elsevier B.V.

\section{Conclusion}

Electrochemical reduction of alkyl and aryl halides solutions in organic solvents is performed at very negative potentials except with $\mathrm{Pd}, \mathrm{Ag}$ and $\mathrm{Cu}$ electrodes where a catalytic effect is observed. Under such conditions, alkyl and aryl radicals, which are formed after dissociative electron transfer according to a concerted or stepwise mechanism, are immediately reduced on 
the electrode surface. Therefore, direct attachment of alkyl and aryl radicals on electrode surface is not an easy task. By using an aryl diazonium salt that cannot be grafted due to the steric hindrance in the ortho position of the diazonium group, it is possible to generate alkyl or aryl radicals issued from alkyl iodides or bromides and aryl iodides after removal of the halogen atom from RX and ArI. This approach enables the modification of electrode surface with alkyl or aryl moieties created at the reduction potential of an aryl diazonium salt using a radical crossover reaction; then $\mathrm{R}^{\bullet}$ or $\mathrm{Ar}^{\bullet}$ radicals are not immediately reduced to carbanions because of a positive potential shift of the operating conditions, $\Delta \mathrm{E}_{\mathrm{p}}>1.7 \mathrm{~V}$.

This method of grafting, at low driving force, of alkyl or aryl groups derived from their halides is interesting especially for those containing functional substituents that do not withstand highly negative potentials. ${ }^{[56]}$ It also applies to the modification of polymers under heating.

\section{Acknowledgment}

The authors dedicate this contribution to the memory of Prof. Jean Michel-Savéant, who has been a key player in electrochemistry and made enormous contributions especially in molecular electrochemistry. His work and numerous inputs will always remain an inspiration for scientists.

\section{Table of Contents}

The grafting of alkyl and aryl halides (I, Br) can be achieved indirectly by reduction of a sterically hindered aryldiazonium salt. The key reaction is the halogen atom transfer from the halide to the aryl radical obtained by reduction of the diazonium salt. Under electrochemical conditions, such indirect reaction is shifted positively by $\sim 2 \mathrm{~V}$ compared to the direct grafting. The indirect reaction can also be performed on polymers under heating.

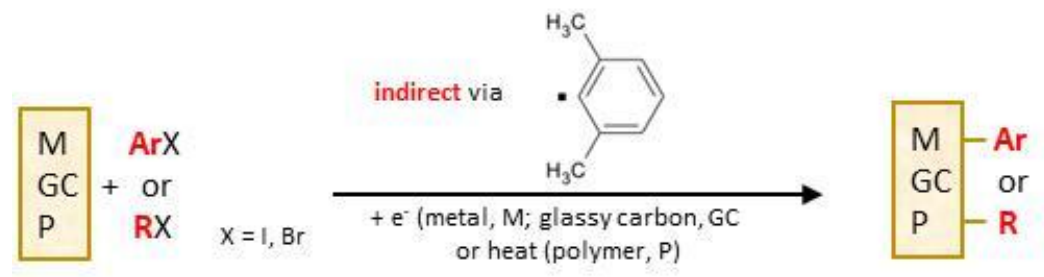




\section{References}

[1] J.-M. Savéant, Acc. Chem. Res. 1993, 26, 455-461.

[2] C. Costentin, M. Robert, J.-M. Savéant, J. Am. Chem. Soc. 2004, 126, 16051-16057.

[3] C.P. Andrieux, J.-M. Savéant, K.B. Su, J. Phys. Chem. 1986, 90, 3815-3823.

[4] L. Pause, M. Robert, J.-M. Savéant, J. Am. Chem. Soc., 1999, 121, 7158-7159.

[5] J.-M. Savéant, J. Phys. Chem. 1994, 98, 3716-3724.

[6] R.J. Enemaerke, T.B. Christensen, H. Jensen, K. Daasbjerg, J. Chem. Soc., Perkin Trans. 2001, 2, 1620-1630.

[7] H. Lund, K. Daasbjerg, T.Lund, D. Occhialini, S.U. Pedersen, Acta Chem. Scandinavica, 1997, 51, 135-144.

[8] C.Y. Liu, M.L. Coote, A. Gennaro, K. Matyjaszewski, J. Am. Chem. Soc., 2008, 130, 12762-12774.

[9] C.P. Andrieux, J. Pinson, J. Am. Chem. Soc., 2003, 125, 14801-14806.

[10] Y. Fu, L. Liu, H.-Z. Yu, Y.-M. Wang, Q.-X. Guo, J. Am. Chem. Soc., 2005, 127, 7227-7234.

[11] P.P. Romanczyk, G. Rotko, S.S. Kurek, Electrochem. Com., 2014, 48, 21-23.

[12] L. Koefoed, K.H. Vase, J. H. Stenlid, T. Brinck, Y. Yoshimura, H. Lund, S. U. Pedersen, K. Daasbjerg, ChemElectroChem, 2017, 4, 3212-3221.

[13] V. Jouikov, J. Simonet, Electrochem. Commun. 2012, 15, 93-96.

[14] J. Simonet, J. Electroanal. Chem. 2005, 583, 34-45.

[15] P. Poizot, L. Laffont-Dantras, J. Simonet, J. Electroanal. Chem. 2008, 624, 52-58.

[16] J. Simonet, J. Electroanal. Chem. 2009, 632, 30- 38.

[17] S. Rondinini, P.R. Mussini, P. Muttini, G. Sello, Electrochim. Acta 2001, 46, 3245-3248.

[18] A.A. Isse, P.R. Mussini, A. Gennaro, J. Phys. Chem. C, 2009, 113, 14983-14992.

[19] A.A. Isse, S. Gottardello, C. Durante, A. Gennaro, Phys. Chem. Chem. Phys., 2008, 10, 2409-2416

[20] S. Neukermans, F. Vorobjov, T. Kenis, R. De Wolf , J. Hereijgers, T. Breugelmans, Elec. Acta, 2020, 332, 135484.

[21] V. Juikov, J. Simonet, Electrochem. Com., 2010, 12, 781-783.

[22] A.A. Isse, C. Durante, A. Gennaro, Electrochem. Commun. 2011, 13, 810-813.

[23] R. Barhdadi, J. Gal, M. Heintz, M. Troupel, J. Périchon, Tetrahedron 1993, 49, 5091-5098.

[24] G.M. McNamee, B.C. Willett, D.M. La Perriere, D.G. Peters, J. Am. Chem. Soc., 1977, 99, 18311835. 
[25] M.M Chehimi, G. Hallais, T. Matrab, J. Pinson, F.I. Podvorica, J. Phys. Chem. C . 2008, 112, 1855918565.

[26] V. Jouikov, J. Simonet, Electrochem. Commun. 2014, 40, 58-62.

[27] F. Hui, J.-M. Noël, P. Poizot, P. Hapiot, J. Simonet, Langmuir 2011, 27, 5119-5125.

[28] J.T. Barnes, K.J. Griffith, J.A. Beeler, B.H.R. Gerroll, A.G. Couto Petro, C.G.Williams, A.R. Siedle, S.L. Tait, D.G. Peters, J. of Electroanal. Chem. 2020, 856, 113531.

[29] V. Jouikov, J. Simonet, Electrochem. Commun. 2014, 46, 132-136.

[30] Y.-F.Huang, D.-Y.Wu, A. Wang, B. Ren, S. Rondinini, Z.-Q. Tian, C. Amatore, J. Am. Chem. Soc. 2010, 132, 17199-17210.

[31] A.A. Isse, G. Berzi, L. Falciola, M. Rossi, P.R. Mussini, A. Gennaro, J Appl Electrochem 2009, 39, 2217.

[32] V. Jouikov, J. Simonet, Langmuir 2012, 28, 931-938.

[33] A. Wang, Y.-F.Huang, U. Kumar Sur, D.-Y.Wu, B. Ren, S. Rondinini, C. Amatore, Z.-Q. Tian, J. Am. Chem. Soc. 2010, 132, 9534-9536.

[34] O. V. Klymenko, O. Buriez, E. Labb, D.-P. Zhan, S. Rondinini, Z.-Q. Tian, I. Svir, C. Amatore, ChemElectroChem 2014, 1, 227 - 240.

[35] V. Jouikov, J. Simonet, Electrochem. Commun. 2011, 13, 1296-1299.

[36] L. Koefoed, S.U. Pedersen, K. Daasbjerg, Langmuir, 2017, 33, 3217-3222.

[37] F. M’Halla, J. Pinson, J.-M. Savéant, J. Am. Chem. Soc. 1980, 102, 4120-4127.

[38] A. Berisha, M.M. Chehimi, J. Pinson, F.I Podvorica, in: A.J. Bard, C.G. Zoski (Eds.), Electroanalytical Chemistry, 26 CRC Press, Boca Raton, FL, 2016.

[39] M. Gomberg, W.E. Bachmann, J. Am. Chem. Soc. 1924, 45, 2339-2343.

[40] A. Berisha, C. Combellas, F. Kanoufi, J. Pinson, S. Ustaze, F. I. Podvorica, Chem. Mater. 2010, 22, 2962-2969

[41] C.J. Collins, Acc. Chem. Res. 1971, 4, 315-322.

[42] D. Hetemi, C. Combellas, F. Kanoufi, J. Pinson, F.I. Podvorica, Elec. Comm. 2016, 68, 5-9.

[43] C. Combellas, D. Jiang, F. Kanoufi, J. Pinson, F.I Podvorica, Langmuir 2009, 25, 286-293.

[44] D. Hetemi, F. Kanoufi, C. Combellas, J. Pinson, F.I. Podvorica, Langmuir 2014, 30, 13907-13913.

[45] C. Amatore, G. Capobianco, G. Farnia, G. Sandona, J.-M. Saveant, M.G. Severin, E. Vianello, J. Am. Chem. Soc. 1985, 107, 1815-1824.

[46] S. Peressini, C. Tavagnacco, G. Costa, C. Amatore, J. Electroanal. Chem. 2002, 532, 295-302.

[47] E. Tatunashvili, C.S.P. McErlean, Org. Biomol. Chem., 2020, 18, 7818-7821.

[48] E. Tatunashvili, B. Chan, P.E. Nashar, C.S.P. McErlean, Org. Biomol. Chem., 2020,18, 1812-1819. 
[49] D. Hetemi, H. Hazimeh, P. Decorse, A. Galtaries, C. Combellas, F. Kanoufi, J. Pinson, F.I. Podvorica, Langmuir 2015, 31, 5046-5415.

[50] D. Hetemi, J. Medard, P. Decorse, C. Combellas, F. Kanoufi, J. Pinson, F.I. Podvorica, Langmuir 2016, 32, 6335-6342.

[51] D. Hetemi, J. Médard, F. Kanoufi, C. Combellas, J. Pinson, F.I. Podvorica, Langmuir, 2016, 32, 512518.

[52] C. Combellas, F. Kanoufi, J. Pinson, F.I. Podvorica, Elec. Com. 2019, 98, 119-123.

[53] J.-M. Savéant, in: D. Bethel (Ed.), Advances in Physical Organic Chemistry, 26 Academic Press, 1990, p. 39.

[54] J. Agullo, S. Canesi, F. Schaper, M. Morin, D. Belanger, Langmuir 2012, 28, 4889-4895.

[55] H. Smida, E. Lebegue, J.-F. Bergamini, F. Barriere, C. Lagrost, Bioelectrochemistry, 2018, 120, $157-165$.

[56] O. Hammerich, J. Ludvik, R. Breinbauer, M. Peters, in 30, 31 and 32th Chapter of Organic Electrochemistry book, Edited by Hammerich, O. and Speider, B. $5^{\text {th }}$ Ed. 2016 Taylor\&Francis Group LLC. 